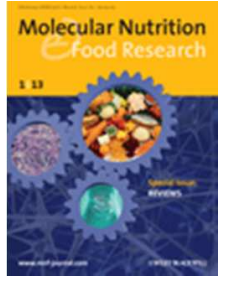

\title{
Dose effect on the uptake and accumulation of hydroxytyrosol and its metabolites in target tissues in rats.
}

\begin{tabular}{|r|l|}
\hline Journal: & Molecular Nutrition and Food Research \\
\hline Manuscript ID: & Draft \\
\hline Watey - Manuscript type: & Food \& Function \\
\hline Complete List of Authors: & $\begin{array}{l}\text { López de las Hazas, Maria-Carmen; University of Lleida, Food Technology } \\
\text { Rubió, Laura; University of Lleida, Food Technology } \\
\text { Krotonoulas, Aristotelis; IMIM-Institut, Hospital del Mar d'Investigaciones } \\
\text { Mèdiques, } \\
\text { de la Torre, Rafael; IMIM-Institut, Hospital del Mar d'Investigaciones } \\
\text { Mèdiques, } \\
\text { Solà, Rosa; Universitat Rovira i Virgili, Unitat de Recerca en Lípids i } \\
\text { Arteriosclerosis } \\
\text { Motilva, Maria J.; University of Lleida, Food Technology }\end{array}$ \\
\hline Keywords: & $\begin{array}{l}\text { Biodistribution, Dose-uptake, Hydroxytyrosol, Phenol metabolites, Tissue } \\
\text { distribution }\end{array}$ \\
\hline &
\end{tabular}


1 Dose effect on the uptake and accumulation of hydroxytyrosol and its metabolites

2 in target tissues in rats

3

4 Maria-Carmen López de las Hazas ${ }^{1}$, Laura Rubió ${ }^{1}$, Aristotelis Krotonoulas ${ }^{2}$, Rafael de 5 la Torre ${ }^{2,3}$, Rosa Solà $^{4}$, María-José Motilva $^{1 *}$

6

$7 \quad{ }^{1}$ Food Technology Department, Agrotecnio Research Center, Escuela Técnica Superior

8 de Ingeniería Agraria, University of Lleida, Av/Alcalde Rovira Roure 191, 25198

9 Lleida, Spain

$10{ }^{2}$ Human Pharmacology and Clinical Neurociences Research Group, IMIM-Institut, 11 Hospital del Mar d'Investigaciones Mèdiques, Doctor Aiguader 88, 08003 Barcelona, 12 Spain. Pompeu Fabra University (CEXS-UPF), Dr. Aiguader 80, 08003 Barcelona, 13 Spain

$14{ }^{3}$ Cardiovascular Risk and Nutrition Research Group, REGICOR Study Group, IMIM15 Research Institute Hospital del Mar, Barcelona, Spain

$16{ }^{4}$ Unitat de Recerca en Lípids i Arteriosclerosis, CIBERDEM, St. Joan de Reus 17 University Hospital, IISPV, Facultat de Medicina i Ciències de la Salut, Universitat 18 Rovira i Virgili, C/ Sant Llorenç 21, 43201 Reus, Spain

20 *Correspondence: Fax: + 34973 702596; E-mail: motilva@tecal.udl.es (Dr. Maria21 José Motilva)

22

23 Abbreviations: VOO: Virgin Olive Oil, HT: Hydroxytyrosol; HT-S: hydroxytyrosol 24 sulfate; HVAlc: Homovanillic alcohol; HVAC. Homovanillic Acid; HVAlc-S: 25 Homovanillic alcohol sulfate; HVAc-S. Homovanillic Acid Sulfate; HT 4-Gluc: 
26 Hydroxytyrosol 4 glucuronide; HT 3-Gluc: Hydroxytyrosol 3 glucuronide; HVAlc-gluc:

27 Homovanillic alcohol glucuronide

28

29 Keywords: Biodistribution / Dose-uptake / Hydroxytyrosol / Phenol metabolites /

30 Tissue disposition

31

14
15
16
17
18
19
20
21
22
23
24
25
26
27
28
29
30
31
32
33
34
35
36
37
38
39
40
41
42
43
44
45
46
47
48
49
50
51
52
53
54
55
56
57
58
59
60


34 The aim of the present study was to investigate the relationship between the 35 hydroxytyrosol (HT) dose intake and the HT metabolites tissue uptake in order to assess

36 if the HT levels detected in tissues after the administration of different doses are

37 relevant and sufficiently compatible with those that have been reported as in vitro

38 modulators of biological functions. Rats were given a refined olive oil enriched with HT

39 at different doses $(1,10$ and $100 \mathrm{mg} / \mathrm{kg})$ and after 5 hours they were sacrificed. Plasma

40 samples and different organs as liver, kidney, heart and brain were obtained, and HT

41 metabolites were analyzed by UPLC-MS/MS. The results showed that HT and its

42 metabolites had a dose-dependent response in both the plasma and tissue deposition for

43 all the organs analyzed. It is noteworthy the appearance of the native bioactive form of

44 HT in circulation and the accumulation in the liver and kidney. The detection of greater

45 amounts of HT sulfate conjugates even at nutritionally-relevant human doses indicates

46 that the bioactivities of these metabolites are also worthy of future research in order to

47 understand the clinical implications of olive oil phenolics, specially to prevent certain 48 hepatic and renal diseases. 
50 In recent years, hydroxytyrosol (HT) and its derivatives have led to a great interest from

51 the virgin olive oil (VOO) producers and manufacturers of nutraceutical supplements.

52 The increasing interest in HT is mainly due to the EFSA Panel on Dietetic Products,

53 Nutrition and Allergies (NDA) inform that established a cause-and-effect relationship

54 between the consumption of olive oil polyphenols and protection of LDL particles from

55 oxidative damage [1]. Based on this positive opinion, the health claim "Olive oil

56 polyphenols contribute to the protection of blood lipids from oxidative stress" was

57 included in the list of health claims [2], being the only authorized health claim in the

58 European Union regarding polyphenols and health.

59 In relation to the mechanisms by which olive phenolic compounds can exercise

60 their cardioprotective activity it is becoming more evident that polyphenols exert their

61 cellular protection by interacting with intracellular signaling pathways involved in

62 pathological processes [3]. After absorption, plasma proteins can be targets of the

63 phenolic metabolites, and there are also possible interactions with proteins in specific

64 target organs in the human body [4]. Therefore, along with the effort to elucidate

65 molecular targets of HT, knowledge about its organ distribution and tissue uptake may

66 increase comprehension of its beneficial effects on health. For this, it is necessary to

67 assess if the HT levels detected in tissues are relevant and sufficiently compatible with

68 those that have been reported as in vitro modulators of biological functions. In relation

69 to the metabolism and tissue uptake of HT, previous studies have been performed in

70 rats, either using intravenously injected $\left[{ }^{14} \mathrm{C}\right]$ hydroxytyrosol [5] or by oral

71 administration of an olive phenol extract [6]. Although the pharmacokinetic response

72 and tissue distribution of HT was thoroughly investigated in these aforementioned

73 studies, no information is available in the literature regarding the dose-dependent uptake

74 of HT and its main metabolites into target tissues. 
In this context, the present study aimed to investigate the relationship between

76 the HT dose intake and tissue uptake in rats, and thus, providing complementary

77 information in relation to the target/dose relationship. For this purpose, liver, kidney, brain and heart were collected after the administration of three different doses: $1 \mathrm{mg}$ HT/kg rat weight (HT-1) compatible with human dietary habits [7], and two higher doses $(10 \mathrm{mg} / \mathrm{kg}$ rat weight: HT-10 and $100 \mathrm{mg} / \mathrm{kg}$ rat weight: HT-100) that could

81 mimic medium and high exposures of HT through dietary supplements. Detailed 82 materials and methods are contained in the Supporting Information.

83 Results of the plasma analysis showed that free HT and its metabolites were 84 detected and were measurable after the three administered doses (Table 1), except for 85 the glucuronide conjugates, which were only detected at the highest doses (HT-10 and 86 HT-100). In the control plasma (vehicle), none of these compounds were detected, 87 which validates them as products of HT metabolism. Sulfation was the most relevant 88 conjugation pathway at the three administered doses compared with the glucuronide 89 conjugates. It is important to highlight that the free form of HT was detected in the 90 plasma after the administration of all three doses and that the recovery of free HT 91 appeared to rise in a dose-dependent fashion (from $0.05 \mu \mathrm{mol} / \mathrm{L} \mathrm{HT}-1$ to $12.9 \mu \mathrm{mol} / \mathrm{L}$ HT-100) as with the metabolites ( $p$ trend $<0.001)$.

The dose effect on the tissue uptake of HT was first studied on two metabolic 94 tissues (liver, kidney) obtained five hours after the intake of the vehicle (refined olive 95 oil) and the different doses of HT (Table 2). In general, the nature of the HT 96 metabolites was similar to the plasma and a significant dose-dependent uptake was 97 observed for all metabolites studied ( $p$ trend $<0.001$ ) except for HVAlc in the kidney 98 (Table 2). Additionally, significant differences were observed for the metabolites 99 quantified at all HT doses compared to the vehicle group $(p<0.001)$. 
100 Interestingly, the free active form of HT was detected in both liver and kidney. If

101 we compare our results with those that have been reported as in vitro modulators of 102 biological functions, the concentrations of HT tested in vitro cell lines showed 103 significant effects in the range of 5-10 $\mu \mathrm{M}$ in the case of kidney [8] and in the range of $1041-5 \mu \mathrm{M}$ for hepatic cell lines [9], which were much higher than those detected in our 105 study (2-83 nM) (Table 2). Despite that, recent studies have reported that HT possesses 106 in vivo hepatoprotective effects [10-12]. So it can be hypothesized that HT metabolites 107 may be active per se, or provide a pool for local or systemic regeneration of HT in vivo. 108 HT metabolites, which might also show biological activities, probably explain the 109 modulation of other pathways/mechanisms from than those previously reported related 110 to direct antioxidant/scavenging mechanisms $[8,13]$. Indeed, the most recent hypothesis 111 regarding the mechanism of action of polyphenols is that they can exert protective 112 effects modulating signal transduction, cell signaling, gene expression and cellular 113 communication in several pathways [14].

114 Besides the metabolic tissues, two target tissues (brain and heart) were studied 115 showing a lower deposition of HT metabolites (Table 3). Regarding the brain, some of 116 the HT metabolites were also detected in the vehicle group suggesting that the low 117 concentrations detected could be produced endogenously from dopamine metabolism 118 [15]. It is remarkable, however, that at the highest dose (HT-100), HT-S, HV-Ac, 119 HVAc-S and HVAlc-S presented significant increases compared to the other 120 administered doses, indicating that only at higher doses some metabolites from the HT 121 intake could cross the blood-brain barrier. In fact, dose-dependent accumulation of HT$122 \mathrm{~S}$ and HVAlc-S was observed in the brain $(p$ trend $<0.001)$ (Table 3). A previous study 123 reported that the administration of $100 \mathrm{mg} / \mathrm{kg}$ of HT in mice enhanced cytoprotection 124 and the resistance of dissociated brain cells to oxidative stress [16]. Thus, it could be 
125 hypothesized that the accumulation of these metabolites in the brain after a 126 pharmacological dose of HT could exert a neuro-protective activity in the central nerve 127 system. In the present study, the free form of HT was not detected in the brain, in 128 contrast to a previous study, in which $100 \mathrm{mg} / \mathrm{kg}$ of HT was administered through the 129 femoral vein [17] and considerable amounts of free HT were detected in the brain. 130 Compared with the oral route of our study, intravenous administration could explain the 131 higher exposure of HT to the brain tissue and its detection in its free form.

132 In contrast to other tissues, HT metabolites were not detected in the heart in HT-1 133 and HT-10 groups (Table 3), being HT-S the main metabolite quantified after the HT134 100. Unlike in the liver and kidney, free HT was not detected in the heart. However, 135 free HT and its metabolites were detected in plasma even at the nutritionally-relevant 136 dose (Table 1), which could explain the cardioprotective effects of VOO phenols 137 previously described at different circulation targets. Reported in vivo studies indicate 138 that HT can reduce endothelial activation [18], inhibit platelet aggregation [19] and 139 reduce the plasma-reduced homocysteine concentration [20], effects that have been 140 associated with cardiovascular protection and could be related to the presence of 141 circulating HT and its metabolites.

142 Interestingly, in samples obtained from HT-100 group, a significant gender effect 143 was observed in the plasma (Table 1), liver and kidney (Table 2). Plasmatic 144 concentrations of free HT and its main metabolites HT-S and HVAc were significantly 145 higher $(p<0.05)$ in females (Table 1). Similarly, the concentrations of free HT and 146 metabolites (HT-S, HVAc, HVAc-S and HVAlc-S) were significantly higher $(p<0.05)$ 147 in the liver from females, this being the tissue where the gender effect was more striking 148 (Table 2). No gender effect was observed in the uptake of HT metabolites in the brain 149 and heart (data not shown). Our results are in line with previous studies in which 
150 genistein and daidzein, two major isoflavones in soy, also presented an enhanced oral

151 bioavailability in females than in males [21]. The main reason that could explain these

152 differences seems to be the different expression profiles of metabolizing enzymes and

153 efflux transporters in the main metabolic disposition organs, such as the intestine, liver

154 and kidney [22]. In other studies, pulsatile versus continuous release of growth hormone

155 in male and female rats, respectively, has been suggested as a major reason for the sex-

156 dependent differences in the expression profiles of the hepatic phase I metabolizing 157 enzymes [23].

158 Summarizing, our study showed that HT and its metabolites could be accumulated

159 in a dose-dependent manner basically in the liver, kidney and brain and were detected in

160 these tissues even at nutritionally-relevant human doses, a dose that was not previously

161 studied in tissue disposition. The detection of free HT in liver and kidney is noteworthy.

162 To date, this appears to be the only biologically active form, and thus, it provides

163 relevant information for optimizing the potential applications of HT to prevent certain

164 hepatic and renal diseases. However, the detection of greater amounts of HT

165 metabolites in tissues, specifically the sulfate conjugates, indicates that the bioactivities

166 of these metabolites are also worthy of future research in order to understand the

167 clinical implications of olive oil phenolics. The obtained results regarding the

168 target/dose relationship of HT and its metabolites, together with the literature data on

169 the biological effects, allow increasing our understanding of the health beneficial effects 170 of HT.

171

172 This study was supported by the Spanish Ministry of Education and Science

173 (AGL2012-40144-C03-03, AGL2012-40144-C03-02 and AGL2012-40144-C03-01 
174 projects), by the University of Lleida through the M.C. López de las Hazas and L. Rubió

175 grant. CIBERobn is an iniciative of Instituto de Salud Carlos III (ISCIII).

176 The authors are grateful for the generous gift of hydroxytyrosol from Seprox

177 Biotech, Madrid, Spain. The authors declare no conflict of interest.

178

179 References

180

181 [1] EFSA Panel on Dietetic Products Nutrition and Allergies (NDA), Scientific opinion 182 on the substantiation of health claims related to polyphenols in olive. Pursuant to 183 Article 13(1) of Regulation (EC) No 1924/2006. EFSA J. 2011, 9 , 2033 Available 184 online: www.efsa. europa.eu/efsajournal.

185 [2] COMMISSION REGULATION (EU) No 432/2012 of 16 May 2012 establishing a 186 list of permitted health claims made on foods, other than those referring to the 187 reduction of disease risk and to children's development and health. Official Journal 188 of the European Union L136.

189 [3] Konstantinidou, V., Covas, M.I., Muñoz-Aguayo, D., Khymenets, O., et al., In vivo 190 nutrigenomic effects of virgin olive oil polyphenols within the frame of the 191 Mediterranean diet: a randomized controlled trial. FASEB J. 2010, 24, 2546 - 2557.

192 [4] Rohn, S., Possibilities and limitations in the analysis of covalent interactions 193 between phenolic compounds and proteins. Food Res. Int. 2014, 65, 13-19.

194 [5] D’Angelo, E., Manna, C., Migliardi, V., Mazzoni, O., et al., Pharmacokinetics and 195 metabolism of hydroxytyrosol, a natural antioxidant from olive oil. Drug. Metabol. 196 Dis. 2001, 29, 1492-1498. 
197 [6] Serra, A., Rubió, L., Borràs, X., Macià, A., et al., Distribution of olive oil phenolic 198 compounds in rat tissues after administration of a phenolic extract from olive cake. 199 Mol Nutr. Food Res. 2012, 56, 486-496.

200 [7] Kotronoulas, A., Pizarro, N., Serra, A., Robledo, P., et al., Dose-dependent 201 metabolic disposition of hydroxytyrosol and formation of mercapturates in rats. 202 Pharmacol. Res. 2013, 77, 47-56.

203 [8] Deiana, M., Incani, A., Rosa, A., Atzeri, A., et al., Hydroxytyrosol glucuronides 204 protect renal tubular epithelial cells against $\mathrm{H}(2) \mathrm{O}(2)$ induced oxidative damage. 205 Chem. Biol. Interact. 2011, 193, 232-239.

206 [9] Giordano, E., Davalos, A., Nicod, N., Visioli, F., Hydroxytyrosol attenuates 207 tunicamycin-induced endoplasmic reticulum stress in human hepatocarcinoma 208 cells. Mol. Nutr. Food Res. 2014, 58, 954-962.

209 [10] Zhao, B., Ma, Y., Xu, Z., Wang, J., et al., Hydroxytyrosol, a natural molecule 210 from olive oil, suppresses the growth of human hepatocellular carcinoma cells via 211 inactivating AKT and nuclear factor-kappa B pathways. Cancer Lett. 2014, 347, $212 \quad 79-87$.

213 [11] Pan, S., Liu, L., Pan, H., Ma, Y., et al., Protective effects of hydroxytyrosol on 214 liver ischemia/reperfusion injury in mice. Mol. Nutr. Food Res. 2013, 57, 1218 $215 \quad 1227$.

216 [12] Kim, M.S., Koppula, S., Sung, S.J., Lee, S.R., et al., Olea europaea Linn 217 (Oleaceae) Fruit Pulp Exhibits Hypocholesterolemic and Hepatoprotective Effects 218 via Regulation of Peroxisome Proliferation-Activated Receptor Alpha in High-Fat 219 Diet-Fed Rats. Trop. J. Pharm. Res. 2014, 12, 13-31.

220 [13] Khymenets, O., Fito, M., Tourino, S., Munoz-Aguayo, D., et al. Antioxidant 221 activities of hydroxytyrosol main metabolites do not contribute to beneficial 
222 health effects after olive oil ingestion. Drug Metab. Dispos. 2010, 38, 1417-1421.

223 [14] Kang, N.J., Shin, S.H., Lee, H.J., Lee, K.W., Polyphenols as small molecular 224 inhibitors of signaling cascades in carcinogenesis. Pharmacol. Ther. 2011, 130, $225 \quad 310-324$.

226 [15] Gallardo, E., Madrona, A., Palma-Valdés, R., Trujillo, M., et al., The effect of 227 hydroxytyrosol and its nitroderivatives on catechol-O-methyl transferase activity 228 in rat striatal tissue. RSC Adv. 2014, 4, 61086-61091.

229 [16] Schaffer, S., Podstawa, M., Visioli, F., Bogani, P., et al., Hydroxytyrosol-Rich 230 Olive Mill Wastewater Extract Protects Brain Cells in Vitro and ex Vivo. J. Agric. $231 \quad$ Food Chem. 2007, 55, 5043-5049.

232 [17] Wu, Y.T., Lin, L.C, Tsai, T.H., Measurement of free hydroxytyrosol in 233 microdialysates from blood and brain of anesthetized rats by liquid chromatography with fluorescence detection. J. Chromatogr. A. 2009, 1216, $3501-3507$.

[18] Carluccio M.A., Siculella, L., Ancora, M.A., Massaro, M. et al., Olive oil and red wine antioxidant polyphenols inhibit endothelial activation: Antiatherogenic properties of Mediterranean diet phytochemicals. Arteriosclerosis, Thrombosis, and Vascular Biology. 2003, 23, 622-629.

[19] Visioli F., Caruso D.,Virgin Olive Oil Study (VOLOS): Vasoprotective potential of extra virgin olive oil in mildly dyslipidemic patients. Eur.J. Clin. Nutrition,

243 [20] Priora R., Summa D., Administration of minor polar compound-enriched extra virgin olive oil decreases platelet aggregation and the plasma concentration of reduced homocysteine in rats. $J$. Nutr. 2008, 138, 36-41. 
246 [21] Kulkarni, K.H., Yang, Z., Niu, T., Hu, M., Effects of estrogen and estrus cycle on

247 pharmacokinetics, absorption, and disposition of genistein in female Sprague-

248 Dawley rats. J Agric Food Chem. 2012, 60, 7949-7956.

249 [22] Buckley, D.B., Klaassen, C.D., Mechanism of gender-divergent UDP250 glucuronosyltransferase mRNA expression in mouse liver and kidney. Drug 251 Metab. Dispos., 2009, 37, 834-840.

252 [23] Waxman D.J., Holloway M.G., Sex differences in the expression of hepatic drug 253 metabolizing enzymes. Mol. Pharmacol. 2009, 76, 215-228. 
255 Table 1. Concentration ( $\mu \mathrm{mol} / \mathrm{L}$ plasma) of HT and its metabolites in rat plasma after 5 256 hours of the administration of different doses of HT and the vehicle (refined oil). Effect 257 of gender in plasma concentration at HT-100 dose.

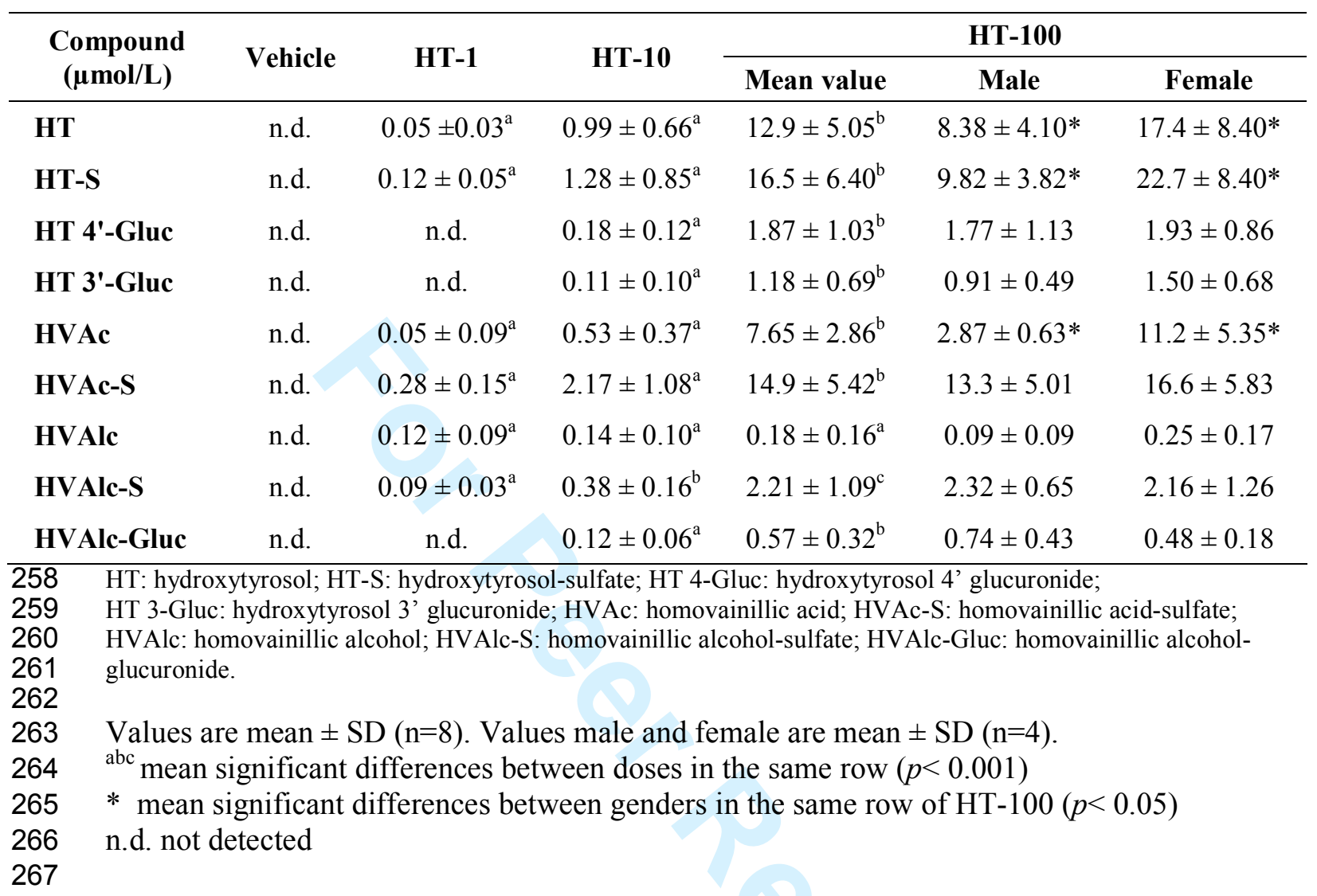


268 Table 2. Concentration ( $\mathrm{nmol} / \mathrm{g}$ fresh tissue) of HT and its metabolites in rat metabolic tissues (liver and kidney) after 5 hours of the administration of different doses of HT and the vehicle (refined oil). Effect of gender in the tissue disposition at HT-100 dose.

\begin{tabular}{|c|c|c|c|c|c|c|}
\hline \multirow{3}{*}{$\begin{array}{l}\text { Compound } \\
\text { (nmol/g fresh } \\
\text { tissue })\end{array}$} & \multicolumn{6}{|c|}{ LIVER } \\
\hline & \multirow[b]{2}{*}{ Vehicle } & \multirow{2}{*}{ HT-1 } & \multirow{2}{*}{ HT-10 } & \multicolumn{3}{|c|}{ HT-100 } \\
\hline & & & & Mean value & Male & Female \\
\hline HT & n.d. & $0.1 \pm 0.01^{\mathrm{a}}$ & $1.11 \pm 0.59^{\mathrm{a}}$ & $17.5 \pm 12.9^{b}$ & $7.66 \pm 1.68^{*}$ & $27.4 \pm 11.5^{*}$ \\
\hline HT-S & n.d. & $0.02 \pm 0.01^{\mathrm{a}}$ & $1.26 \pm 0.70^{\mathrm{a}}$ & $27.4 \pm 26.5^{b}$ & $8.76 \pm 1.84^{*}$ & $46.1 \pm 26.6^{*}$ \\
\hline HT 4-Gluc & n.d. & n.d. & n.d. & $0.21 \pm 0.09$ & $0.16 \pm 0.12$ & $0.26 \pm 0.03$ \\
\hline HT 3-Gluc & n.d. & n.d. & n.d. & $0.22 \pm 0.14$ & $0.14 \pm 0.07$ & $0.31 \pm 0.14$ \\
\hline HVAc & n.d. & n.d. & $0.03 \pm 0.05^{\mathrm{a}}$ & $2.67 \pm 3.20^{\mathrm{b}}$ & $0.50 \pm 0.17 *$ & $4.85 \pm 3.46^{*}$ \\
\hline HVAc-S & n.d. & $0.04 \pm 0.02$ & $0.56 \pm 0.33^{\mathrm{a}}$ & $6.71 \pm 3.28^{\mathrm{b}}$ & $4.92 \pm 3.65^{*}$ & $8.49 \pm 1.63^{*}$ \\
\hline HVAlc & n.d. & n.d. & & & & n.d. \\
\hline HVAlc-S & n.d. & n.d. & $0.32 \pm 0.13^{\mathrm{a}}$ & $5.23 \pm 5.28^{b}$ & $1.80 \pm 0.27^{*}$ & $8.66 \pm 5.74^{*}$ \\
\hline HVAlc-Gluc & n.d. & n.d. & n.d. & $0.04 \pm 0.03$ & $0.02 \pm 0.01$ & $0.07 \pm 0.02$ \\
\hline \multirow{3}{*}{$\begin{array}{c}\text { Compound } \\
(\text { nmol/g fresh } \\
\text { tissue) }\end{array}$} & \multicolumn{2}{|l|}{$P \gamma$} & \multicolumn{2}{|c|}{ KIDNEY } & & \\
\hline & \multirow{2}{*}{ Vehicle } & \multirow{2}{*}{ HT-1 } & \multirow{2}{*}{ HT-10 } & \multicolumn{3}{|c|}{ HT-100 } \\
\hline & & & & Mean value & Male & Female \\
\hline HT & n.d. & n.d. & $2.73 \pm 2.33^{\mathrm{a}}$ & $33.9 \pm 10.3^{b}$ & $26.1 \pm 3.28^{*}$ & $41.8 \pm 10.3 *$ \\
\hline HT-S & $0.14 \pm 0.16^{a}$ & $0.48 \pm 0.1^{\mathrm{a}}$ & $10.1 \pm 5.74^{b}$ & $82.8 \pm 38.9^{\mathrm{c}}$ & $78.9 \pm 5.70$ & $86.8 \pm 29.7$ \\
\hline HT 4-Gluc & n.d. & $0.02 \pm 0.05^{\mathrm{a}}$ & $0.25 \pm 0.12^{b}$ & $0.89 \pm 0.39^{c}$ & $0.88 \pm 0.09$ & $1.09 \pm 0.10$ \\
\hline HT 3-Gluc & n.d. & $0.02 \pm 0.05^{\mathrm{a}}$ & $0.25 \pm 0.12^{\mathrm{b}}$ & $0.99 \pm 0.45^{\mathrm{c}}$ & $0.94 \pm 0.07$ & $1.04 \pm 0.31$ \\
\hline HVAc & $0.26 \pm 0.17^{\mathrm{a}}$ & $0.33 \pm 0.13^{\mathrm{a}}$ & $1.26 \pm 0.76^{b}$ & $7.90 \pm 2.25^{c}$ & $6.73 \pm 2.89$ & $9.07 \pm 1.65$ \\
\hline HVAc-S & $1.22 \pm 0.51^{\mathrm{a}}$ & $0.98 \pm 0.31^{\mathrm{a}}$ & $2.32 \pm 0.74^{b}$ & $6.90 \pm 1.33^{\mathrm{c}}$ & $8.49 \pm 2.98$ & $5.30 \pm 0.05$ \\
\hline HVAlc & $0.23 \pm 0.27^{\mathrm{a}}$ & $0.21 \pm 0.22^{\mathrm{a}}$ & $0.46 \pm 0.17^{b}$ & $0.30 \pm 0.30^{\mathrm{a}}$ & $0.20 \pm 0.23$ & $0.40 \pm 0.01$ \\
\hline HVAlc-S & $0.26 \pm 0.02^{\mathrm{a}}$ & $0.45 \pm 0.09^{\mathrm{a}}$ & $3.23 \pm 1.38^{\mathrm{b}}$ & $20.1 \pm 4.98^{\mathrm{c}}$ & $19.3 \pm 4.63$ & $21.9 \pm 12.7$ \\
\hline HVAlc-Gluc & n.d. & $0.14 \pm 0.03^{\mathrm{a}}$ & $0.22 \pm 0.03^{\mathrm{b}}$ & $0.39 \pm 0.06^{\mathrm{c}}$ & $0.37 \pm 0.10$ & $0.41 \pm 0.07$ \\
\hline \multicolumn{7}{|c|}{$\begin{array}{l}\text { HT: hydroxytyrosol; HT-S: hydroxytyrosol-sulfate; HT 4-Gluc: hydroxytyrosol 4' glucuronide; } \\
\text { HT 3-Gluc: hydroxytyrosol 3' glucuronide; HVAc: homovainillic acid; HVAc-S: homovainillic acid-sulfate; } \\
\text { HVAlc: homovainillic alcohol; HVAlc-S: homovainillic alcohol-sulfate; HVAlc-Gluc: homovainillic } \\
\text { alcohol-glucuronide. }\end{array}$} \\
\hline \multicolumn{7}{|c|}{$\begin{array}{l}\text { Values are mean } \pm \mathrm{SD}(\mathrm{n}=8) \text {. Values male and female are mean } \pm \mathrm{SD}(\mathrm{n}=4) \text {. } \\
\text { abc mean significant differences between doses in the same row }(p<0.001) \\
\text { * mean significant differences between genders in the same row of HT-100 }(p<0.05) \\
\text { n.d. not detected }\end{array}$} \\
\hline
\end{tabular}


281 Table 3. Concentration (nmol/g fresh tissue) of HT and its metabolites in rat 282 target tissues (heart and brain) after 5 hours of the administration of 283 different doses of HT and the vehicle (refined oil).

\begin{tabular}{|c|c|c|c|c|}
\hline \multirow{2}{*}{$\begin{array}{c}\text { Compound } \\
\text { (nmol/g fresh tissue) }\end{array}$} & \multicolumn{4}{|c|}{ BRAIN } \\
\hline & Vehicle & HT-1 & HT-10 & HT-100 \\
\hline HT & n.d. & n.d. & n.d. & n.d. \\
\hline HT-S & $0.26 \pm 0.00^{\mathrm{a}}$ & $0.32 \pm 0.05^{\mathrm{a}}$ & $0.35 \pm 0.10^{\mathrm{a}}$ & $1.26 \pm 0.72^{b}$ \\
\hline HT 4-Gluc & n.d. & n.d. & n.d. & $0.14 \pm 0.03$ \\
\hline HT 3-Gluc & n.d. & n.d. & n.d. & $0.15 \pm 0.02$ \\
\hline HVAc & $0.34 \pm 0.01^{\mathrm{a}}$ & $0.39 \pm 0.04^{\mathrm{a}}$ & $0.32 \pm 0.02^{\mathrm{a}}$ & $0.40 \pm 0.05^{b}$ \\
\hline HVAc-S & $0.50 \pm 0.03^{\mathrm{a}}$ & $0.72 \pm 0.10^{b}$ & $0.49 \pm 0.08^{a}$ & $0.58 \pm 0.12^{b}$ \\
\hline HVAlc & n.d & n.d. & n.d. & n.d. \\
\hline HVAlc-S & $0.14 \pm 0.08^{\mathrm{a}}$ & $0.22 \pm 0.01^{\mathrm{a}}$ & $0.41 \pm 0.12^{b}$ & $2.58 \pm 1.26^{\mathrm{c}}$ \\
\hline HVAlc-Gluc & n.d. & n.d. & n.d. & n.d. \\
\hline \multirow{2}{*}{$\begin{array}{c}\text { Compound } \\
\text { (nmol/g fresh tissue) }\end{array}$} & \multicolumn{4}{|c|}{ HEART } \\
\hline & Vehicle & HT-1 & HT-10 & HT-100 \\
\hline HT & n.d. & n.d. & n.d. & n.d \\
\hline HT-S & n.d. & n.d. & n.d. & $2.73 \pm 2.19$ \\
\hline HT 4-Gluc & n.d. & n.d. & n.d. & $0.02 \pm 0.02$ \\
\hline HT 3-Gluc & n.d. & n.d. & n.d & n.d \\
\hline HVAc & n.d. & n.d. & n.d. & $0.08 \pm 0.10$ \\
\hline HVAc-S & n.d. & n.d. & n.d. & $0.19 \pm 0.22$ \\
\hline HVAlc & n.d. & n.d. & n.d. & n.d \\
\hline HVAlc-S & n.d. & n.d. & n.d. & $0.42 \pm 0.33$ \\
\hline HVAlc-Gluc & n.d. & n.d. & n.d. & n.d \\
\hline $\begin{array}{l}\text { HT: hydroxytyrosol; HT } \\
\text { HT 3-Gluc: hydroxytyro } \\
\text { HVAc-S: homovainillic } \\
\text { HVAlc-S: homovainillic }\end{array}$ & $\begin{array}{l}\text { S: hydroxytyros } \\
\text { ol 3' glucuronic } \\
\text { cid-sulfate; HV } \\
\text { alcohol-sulfate; }\end{array}$ & $\begin{array}{l}\text { ol-sulfate; HT 4- } \\
\text { e; HVAc: homo } \\
\text { Alc: homovainill } \\
\text { HVAlc-Gluc: ho }\end{array}$ & $\begin{array}{l}\text { Gluc: ydroxytyr } \\
\text { ainillic acid } \\
\text { ic alcohol; } \\
\text { movainillic alcol }\end{array}$ & hol-glucuronide \\
\hline $\begin{array}{l}\text { Values are mean } \pm \mathrm{S} \\
\text { abc mean significant } \\
\text { n.d. not detected }\end{array}$ & $\begin{array}{l}(\mathrm{n}=8) \\
\text { ffferences } \mathrm{b}\end{array}$ & nen doce & hesomero & \\
\hline
\end{tabular}

